Ophthalmology. 2012 April ; 119(4): 682-687. doi:10.1016/j.ophtha.2011.09.024.

\title{
Conjunctival Stromal Tumor
}

\author{
Martina C. Herwig, MD $^{1,2}$, Jill R. Wells, $\mathbf{M D}^{1}$, and Hans E. Grossniklaus, MD, MBA ${ }^{1}$ \\ ${ }^{1}$ Department of Ophthalmology, Emory University, 1365 Clifton Road, BT 428, Atlanta, GA 30322 \\ ${ }^{2}$ Department of Ophthalmology, University of Bonn, Ernst-Abbe-Str. 2, 53127 Bonn, Germany
}

\section{Abstract}

Purpose-To describe the clinical, histopathologic, immunohistochemical, and ultrastructural features of a case series of benign stromal tumors in the bulbar conjunctiva.

Design-Observational case series.

Participants-Four patients with a conjunctival lesion that were classified histologically as low grade stromal tumors consisting of spindle-shaped cells with occasional pseudonuclear inclusion and multinucleated cells in a partly myxoid matrix.

Methods-Four cases of low grade conjunctival stromal tumors were retrospectively identified in an ophthalmic pathology laboratory database. Patients' records were analyzed for demographic data, clinical appearance and the post-operative course. Formalin-fixed paraffin-embedded specimens were routinely processed and stained with hematoxylin and eosin (H\&E) and periodic acid Schiff (PAS). Immunohistochemical stains for vimentin, S100, CD34, SMA (smooth muscle actin), CD68, and factor XIIIa were performed. Transmission electron microscopy (TEM) was performed on three of the cases.

Main Outcome Measures-Histopathologic evaluation (including immunostains and TEM) and clinical correlation.

Results-All four tumors occurred in the bulbar conjunctiva of patients between 41 to 53 years of age. None of the patients developed recurrence after excisional biopsy. Histologically, all tumors exhibited spindle-shaped cells with pseudonuclear inclusions and occasional multinuclear cells. Mitotic figures were not observed. The stroma appeared myxoid to collagenous.

Immunohistochemical stains were positive for CD34, vimentin, and focally for CD68, but were negative for S100 and SMA.

Conclusions-We propose to classify these benign lesions which share distinct histopathologic features as "conjunctival stromal tumor (COST)". A reactive/inflammatory component needs to be considered in the pathogenesis of this lesion.

(C) 2011 American Academy of Ophthalmology, Inc. Published by Elsevier Inc. All rights reserved.

Address for reprints: Hans E. Grossniklaus, MD, MBA, Emory Eye Center, L.F. Montgomery Laboratory, BT 428, 1365 Clifton Road, Atlanta, Georgia 30322, phone number: 404-778-4611, fax number: 404-778-4610, ophtheg @ emory.edu.

Meeting Presentation: Presented in part at the annual meeting of The Association for Research in Vision and Ophthalmology (ARVO; Fort Lauderdale, FL, May 4, 2011).

Conflict of Interest: No conflicting relationship exists for any author.

None of the authors have any financial interests to disclose.

Publisher's Disclaimer: This is a PDF file of an unedited manuscript that has been accepted for publication. As a service to our customers we are providing this early version of the manuscript. The manuscript will undergo copyediting, typesetting, and review of the resulting proof before it is published in its final citable form. Please note that during the production process errors may be discovered which could affect the content, and all legal disclaimers that apply to the journal pertain. 


\section{Introduction}

Mesenchymal proliferations of the conjunctiva are rare. The differential diagnosis includes conjunctival (cellular) myxoma, neurothekeoma, subconjunctival herniated orbital fat, fatfree spindle cell lipoma, pseudotumor, neurofibroma, dendrocytoma, solitary fibrous tumor, fibrous histiocytoma, nodular fasciitis, hemangiopericytoma, giant cell angiofibroma, and rhabdomyosarcoma. ${ }^{1-13}$ Due to the location of the conjunctiva on the ocular surface and its role in antigen recognition, various factors and stimuli such as inflammation need to be considered as a contributor to the pathogenesis of conjunctival tumors. Classification of conjunctival tumors helps predict the clinical course and allows for recommendations regarding treatment and follow-up examination. Herein we describe four conjunctival lesions with mesenchymal derivation that were not able to be categorized within the above mentioned differential diagnoses. We introduce the term "conjunctival stromal tumor (COST)" to classify this unique group of lesions.

\section{Methods}

After review of the database between 1941 and 2011 of the L.F. Montgomery Ophthalmic Pathology Laboratory, Emory University, Atlanta, GA, four cases of unclassified low grade conjunctival stromal tumors revealing distinct histopathologic features such as spindleshaped cells with occasional pseudonuclear inclusions, multinucleated cells, and a partly myxomatous matrix were identified. The medical records of the corresponding patients were retrospectively reviewed with regard to patient's history, age, gender, race, localization of the lesion, its clinical appearance, clinical diagnosis, treatment, and outcome. The specimens had been submitted in $10 \%$ formaldehyde and were grossly examined for size and color. They were routinely processed for light microscopic examination and stained with hematoxylin and eosin (H\&E) and periodic acid-Schiff (PAS). The histological specimens were analyzed for size, cell type, cytologic features, and immunohistochemical findings. The excisional biopsies were independently reviewed by all authors. Immunohistochemical stains for CD34 (DAKO; 1:320), CD68 (DAKO; 1:2560), desmin (DAKO, Carpinteria, CA; 1:640), factor XIIIa (Calbiochem, La Jolla, CA; 1:400), Ki67 (DAKO; 1:160), myosin (DAKO; 1:400), SMA (DAKO; 1:160), S100 (DAKO; 1:3200), vimentin (DAKO; 1:320), as well as alcian blue (alcian blue stain $\mathrm{pH} 2.5$ procedure; American Master Tech, Lodi, CA) and colloidal iron (American Master Tech) stains were performed. Formalin-fixed paraffinembedded tissue from cases 1-3 was recovered and submitted for transmission electron microscopic processing. Institutional Review Board (IRB)/Ethics Committee approval was obtained for this study. The research adhered to the tenets of the Declaration of Helsinki

\section{Results \\ Demographic data}

This unique mesenchymal conjunctival tumor was observed in four patients ( 1 female, 3 males) aged from 41 to 53 years (mean value: 47 years) between 1941 and 2011 in the L.F. Montgomery Laboratory, Atlanta, GA. (Tab. 1). All lesions were soft and localized on the bulbar conjunctiva. The color varied from whitish to reddish. The specimens were analyzed histologically for cytologic features and extracellular matrix characteristics (Tab. 2) as well as immunohistochemical (Tab. 3) and transmission electron microscopy (TEM) findings.

Case 1-A 41-year-old Caucasian male presented with a cystic, tender conjunctival lesion (Fig. 1, Tab. 1) localized over the insertion of his right lateral rectus muscle for four years. The whitish-yellow mass was accompanied by overlying mild injection without any signs of malignancy. Local or systemic treatment was not utilized since the patient did not complain about pain or foreign body sensation. As the mass interfered with the patient's glasses, an 
excisional biopsy was performed. Follow-up (15 years) was uneventful. Histologic examination showed a myxoid to collagenous fibrovascular tissue infiltrated by pleomorphic cells (Fig. 1, Tab. 2). Some cells were multinucleated and exhibited pseudonuclear inclusions. Occasionally, a floret-like configuration of cells could be observed. There were no mitotic figures in the mass. Some cells stained positive with alcian blue and colloidal iron, although the extracellular matrix was negative. Immunohistochemical stains were positive for CD34 and myosin in many cells, and negative for desmin, S100, and smooth muscle actin (SMA) (Fig. 1, Tab. 3). Factor XIIIa was expressed in occasional cells. Transmission electron microscopy showed spindle-shaped cells with mitochondria, rough endoplasmic reticulum (RER), and free ribosomes. Vacuolations were present within in the nucleus. Collagen bundles could be observed. There were no intercellular junctions present nor did the cells produce basal lamina.

Case 2-A 47-year-old man, complaining about irritation and redness of his left eye, presented with a lesion involving the conjunctiva and cornea (Tab. 1). A lupus erythematosis-related posterior blepharitis has been treated with cyclosporine $0.05 \%$ bid in his left eye. His systemic medication was hydroxychloroquine sulfate $200 \mathrm{mg}$ bid. As the clinical differential diagnosis included dysplastic epithelium and intraepithelial neoplasia, an excisional biopsy of the lesion was performed. The patient was followed for seven years and underwent an amniotic membrane graft reconstruction due to stem cell deficiency in the left eye five years after the intervention. Histologically, the conjunctival tissue consisted of loosely arranged pleomorphic spindle cells in a myxoid extracellular matrix with wiry collagen fibers (Fig. 2, available at http://aaojournal.org; Tab. 2). Some of the cells contained pseudonuclear inclusions. There were also some multinucleated cells present. Mitotic figures were absent. Some cells and the extracellular matrix stained positive with alcian blue and colloidal iron. Immunohistochemical stains were positive for vimentin, CD34, and CD68, and negative for S100, SMA, myosin, and factor XIIIa (Fig. 2, available at http://aaojournal.org; Tab. 3). The corneal specimen displayed mild reactive changes in the basilar keratocytes.

Transmission electron microsopy showed spindle-shaped fibroblast-like cells with intracellular inclusions in a collagenous matrix (Fig. 2E, available at http://aaojournal.org). There were no intercellular junctions present nor did the cells produce basal lamina.

Case 3-A 53-year-old Caucasian male developed a $1.25 \times 1.5 \mathrm{~mm}$ elevated, non-tender conjunctival nodular lesion with accompanied redness one week after cataract surgery (Fig. 3 , Tab. 1). Ocular history revealed blepharitis and regular use of soft contact lenses. Local steroid application (prednisolone acetate 1\%, qid) - in addition to gatifloxacin $0.3 \%$ and ketorolac tromethamine $0.5 \%$ that were prescribed after cataract surgery - resulted in a diminished reddish appearance but the size of the lesion itself did not regress. Possible clinical diagnoses of this primarily unclassified conjunctival lesion included foreign body reaction versus lymphatic obstruction. Excisional biopsy was performed followed by intense topical steroid treatment to treat inflammation that resulted in a non-ulcerated conjunctival scar. No recurrence was observed with 5 years of follow-up. Histologic examination revealed a proliferation of pleomorphic spindle cells in a myxoid to collagenous matrix (Fig. 3 , Tab. 2). The spindle cells had round to oval nuclei with inconspicuous nucleoli and did not exhibit mitotic figures. Pseudonuclear inclusions and occasional multinucleated cells could be observed. Scattered aggregates of lymphocytes and histiocytes were present. The extracellular matrix and sparse cells stained positive with alcian blue and colloidal iron. Immunohistochemical stains were positive for vimentin, CD34, and CD68 in scattered macrophages, but were negative for S100, SMA and myosin. A few cells expressed factor XIIIa (Fig. 3, Tab. 3). Transmission electron microscopy showed findings similar to case 2 
(Fig. 3G). However, some cells displayed reactive findings with a plump shape, a higher amount of rough endoplasmic reticulum, and a more prominent nucleolus.

Case 4-A 45-year-old woman presented with a slowly enlarging whitish bulbar conjunctival cyst (Tab. 1). During surgery, a gelatinous, mucoid consistency was noted and the lesion could not be completely excised because of posterior extension. Histologic examination of the specimen showed fibrovascular, myxoid to collagenous tissue containing scattered cells with spindle shaped to stellate to fusiform nuclei with bland nucleoli (Fig. 4, available at http://aaojournal.org; Tab. 2). Many of these nuclei exhibited pseudonuclear inclusions. There were scattered multinucleated cells as well as clusters of cells arranged in florets present within the lesion. Occasional inflammatory cells and histiocytes were noted. An alcian blue and colloidal iron stain were positive for the extracellular matrix and some cells. Immunohistochemical stains were positive for vimentin, CD34, and CD68, and negative for S100, SMA, and myosin. Occasional cells were positive for factor XIIIa (Fig. 4, available at http://aaojournal.org; Tab. 3). Ki67 was expressed only in a few cells indicating to a proliferation rate of less than $5 \%$.

\section{Discussion}

The lesions in our case series occurred in middle-aged patients and exhibited a spectrum of clinical appearances. The two patients without a remarkable ocular history (case 1 and 4) revealed whitish to yellow lesions. Reddish lesions were present in the two patients with blepharitis (case 2 and 3 ) in accordance with an additional inflammatory stimulus. All tumors were located in the bulbar conjunctiva. This location predisposes to exposure to several factors in the tear film and other environmental factors that may contribute to the development of these lesions. Blepharitis (case 2 and 3) as an additional inflammatory stimulus may also account for the pathogenesis of these conjunctival lesions. In addition, CD68 positive macrophages and factor XIIIa positive dendritic cells were present to some extent (with the fewest amount of macrophages in the biopsy of patient 3 who was pretreated with topical corticosteroids). With respect to the etiology of these lesions, an inflammatory pathogenesis or a reactive process is possible.

Histologically, our four conjunctival neoplasms consisted of spindle-shaped cells with pseudonuclear inclusions and multinucleated cells in a collagenous-to-myxoid stroma. Immunohistochemical stains were positive for vimentin, CD34, acid mucopolysaccharides, and focally for CD68 (and factor XIIIa), but were negative for S100 and SMA. The differential diagnoses comprised of conjunctival (cellular) myxoma, ${ }^{5}$ neurothekeoma, ${ }^{3}$ subconjunctival herniated orbital fat, ${ }^{7}$ fat-free spindle cell lipoma, ${ }^{2}$ pseudotumor, neurofibroma, ${ }^{8}$ dendrocytoma, ${ }^{13}$ nevus with neuronal degeneration, ${ }^{14}$ solitary fibrous tumor, ${ }^{11}$ fibrous histiocytoma, ${ }^{1,6,9}$ nodular fasciitis, ${ }^{14}$ hemangiopericytoma, ${ }^{4}$ giant cell angiofibroma, ${ }^{10}$ and rhabdomyosarcoma. ${ }^{12}$ Our benign conjunctival lesions were differentiated from these entities by cytologic and immunohistochemical features. Conjunctival myxoma that is important to rule out because of a well-known possible association with the Carney complex comprising life-threatening conditions such as an atrial myxoma ${ }^{15}$, is the main differential diagnosis because our conjunctival stromal tumors revealed a partial myxomatous matrix. However, the lesions in our patients were more cellular than myxomas. ${ }^{5}$ Multinucleated cells are rarely found in myxomas. ${ }^{16}$ Pseudonuclear inclusions have been described in conjunctival myxomas. ${ }^{17,} 18$ Hence, the two conjunctival myxomas published by Herwig et $\mathrm{al}^{5}$ were subsequently stained for CD34 in order to differentiate them from our four cases. Both lesions were negative for CD34. However, further investigations of conjunctival myxomas for CD34 are recommended to entirely exclude that COST may be a variant of myxomas. Solitary fibrous tumor, hemangiopericytoma, giant cell angiofibroma, fibrous histiocytoma, and nodular fasciitis 
consist of spindle shaped cells in a collagenous matrix that are except for reactive nodular fasciitis positive to different degrees for CD $34 .{ }^{19}$ However, these neoplasms can be distinguished from our lesions by their morphologic growth patterns and cytologic features. In particular, giant cell angiofibroma can occur in the orbit ${ }^{10,20,21}$ and is composed of spindle cells with pseudonuclear inclusions and giant cells with occasional florets. However, these tumors are usually more cellular and exhibit a high vascular density with vascular-like spaces that allows for a distinction from the described lesions herein. Conjunctival rhabdomyosarcoma is a rare malignant lesion that can also occur in adults and represents conjunctival involvement of an orbital rhabdomyosarcoma. ${ }^{12}$ Although one of our tumors showed a strong positivity for myosin (case 1), our tumors exhibited a very low proliferation rate in general, did not show mitotic figures, and exhibited a benign histologic appearance.

We interpreted the four mesenchymal proliferations as benign proliferation of spindle cells of the conjunctival stroma that share only some histopathological and immunohistochemical characteristics with previously described entities of the conjunctiva. We propose to categorize these CD34, vimentin and partly CD68 positive benign mesenchymal proliferations with pseudonuclear inclusions and multinucleated giant cells (that partly exhibit a floret-like configuration) as "conjunctival stromal tumor (COST)". Although these lesions are benign, complete excisional biopsy of this lesion is recommended if possible, as we cannot exclude the possibility of local recurrence if incompletely excised. Ophthalmologic follow-up examination is also recommended. Identifying conjunctival lesions as COST may prevent overdiagnosis and consecutive overtreatment. Thus, this entity should be included in the differential diagnoses of benign lesions of the bulbar conjunctiva in patients usually in their $5^{\text {th }}$ to $6^{\text {th }}$ decade.

\section{Acknowledgments}

Financial Support: Supported in part by an unrestricted departmental grant from Research to Prevent Blindness, Inc, New York, NY (HEG): Departmental Core Grant, NIH P30EY06360, and the German Research Foundation (DFG), Bonn, Germany (MCH: HE 5775/3-1).

The sponsor or funding organization had no role in the design of conduct of this research.

The authors wish to thank Karin U. Loeffler, MD (University of Bonn, Department of Ophthalmology) for preparing additional CD34 stains of two previously characterized conjunctival myxomas ${ }^{5}$ as well as Frederick A. Jakobiec, MD (Massachussetts Eye and Ear Infirmary) and Sharon W. Weiss, MD (soft tissue pathologist at Emory University, Department of Pathology) for their helpful comments.

\section{References}

1. Al-Quran SZ, Russo JJ, Bandarchi-Chamkhaleh B, Hassanein AM. CD34-positive myxoid dermatofibrohistiocytoma of the skin: an indolent post-traumatic tumor that can be mistaken for dermatofibrosarcoma protuberans. J Cutan Pathol. 2009; 36:84-6. [PubMed: 19125740]

2. Billings SD, Folpe AL. Diagnostically challenging spindle cell lipomas: a report of 34 "low-fat" and "fat-free" variants. Am J Dermatopathol. 2007; 29:437-42. [PubMed: 17890910]

3. Fetsch JF, Laskin WB, Hallman JR, et al. Neurothekeoma: an analysis of 178 tumors with detailed immunohistochemical data and long-term patient follow-up information. Am J Surg Pathol. 2007; 31:1103-14. [PubMed: 17592278]

4. Grossniklaus HE, Green WR, Wolff SM, Iliff NT. Hemangiopericytoma of the conjunctiva: two cases. Ophthalmology. 1986; 93:265-7. [PubMed: 3951833]

5. Herwig MC, Fischer HP, Holz FG, Loeffler KU. Conjunctival myxoma: two cases. Histopathologial examination and clinical course [in German]. Ophthalmologe. 2010; 107:843-7. [PubMed: 20376460]

6. Iwamoto T, Jakobiec FA, Darrell RW. Fibrous histiocytoma of the corneoscleral limbus: the ultrastructure of a distinctive inclusion. Ophthalmology. 1981; 88:1260-8. [PubMed: 6275324] 
7. Schmack I, Patel RM, Folpe AL, et al. Subconjunctival herniated orbital fat: a benign adipocytic lesion that may mimic pleomorphic lipoma and atypical lipomatous tumor. Am J Surg Pathol. 2007; 31:193-8. [PubMed: 17255763]

8. Shaktawat SS, Golka D. Floret-like multinucleated giant cells in neurofibroma. Diagn Pathol. 2007; 2:47. [PubMed: 18067673]

9. Silverman JS, Brustein S. Myxoid dermatofibrohistiocytoma: an indolent post-traumatic tumor composed of CD34+ epithelioid and dendritic cells and factor XIIIa+ dendrophages. J Cutan Pathol. 1996; 23:551-7. [PubMed: 9001986]

10. Farmer JP, Lamba M, McDonald H, Commons AS. Orbital giant cell angiofibroma: immunohistochemistry and differential diagnosis. Can J Ophthalmol. 2006; 41:216-20. [PubMed: 16767212]

11. Piperi E, Rohrer MD, Pambuccian SE, Koutlas IG. Vascular solitary fibrous tumor with "floret" cells or giant cell angiofibroma? A lingual example highlighting the overlapping characteristics of these entities and positive immunoreaction for estrogen and progesterone receptors. Oral Surg Oral Med Oral Pathol Oral Radiol Endod. 2009; 107:685-90. [PubMed: 19272802]

12. Cameron JD, Wick MR. Embryonal rhabdomyosarcoma of the conjunctiva: a clinicopathologic and immunohistochemical study. Arch Ophthalmol. 1986; 104:1203-4. [PubMed: 3527122]

13. Cerio R, Spaull J, Jones EW. Histiocytoma cutis: a tumour of dermal dendrocytes (dermal dendrocytoma). Br J Dermatol. 1989; 120:197-206. [PubMed: 2564281]

14. Grossniklaus HE, Green WR, Luckenbach M, Chan CC. Conjunctival lesions in adults: a clinical and histopathologic review. Cornea. 1987; 6:78-116. [PubMed: 3301209]

15. Kennedy RH, Flanagan JC, Eagle RC Jr, Carney JA. The Carney complex with ocular signs suggestive of cardiac myxoma. Am J Ophthalmol. 1991; 111:699-702. [PubMed: 2039038]

16. Hemachandran M, Kakkar N, Khandelwal N. Giant-cell-rich myxoma of right atrium: an ultrastructural analysis. Cariovasc Pathol. 2003; 12:287-9.

17. Mottow-Lippa L, Tso MO, Sugar J. Conjunctival myxoma: a clinicopathologic study. Ophthalmology. 1983; 90:1452-8. [PubMed: 6677844]

18. Pe'er J, Hidayat AA. Myxomas of the conjunctiva. Am J Ophthalmol. 1986; 102:80-6. [PubMed: 3728629]

19. Weiss, SW.; Goldblum, JR. Enzinger and Weiss's Soft Tissue Tumors. 5. Phildadelphia, PA: Mosby; 2008. p. 177-86.p. 331-42.p. 1120-36.

20. Schmack I, Helmke B, Kolling G, et al. Orbital giant cell angiofibroma after blunt bulbus trauma [in German]. Klin Monbl Augenheilkd. In press.

21. Weiss, SW.; Goldblum, JR. Enzinger and Weiss's Soft Tissue Tumors. 5. Phildadelphia, PA: Mosby; 2008. p. 1135-6. 


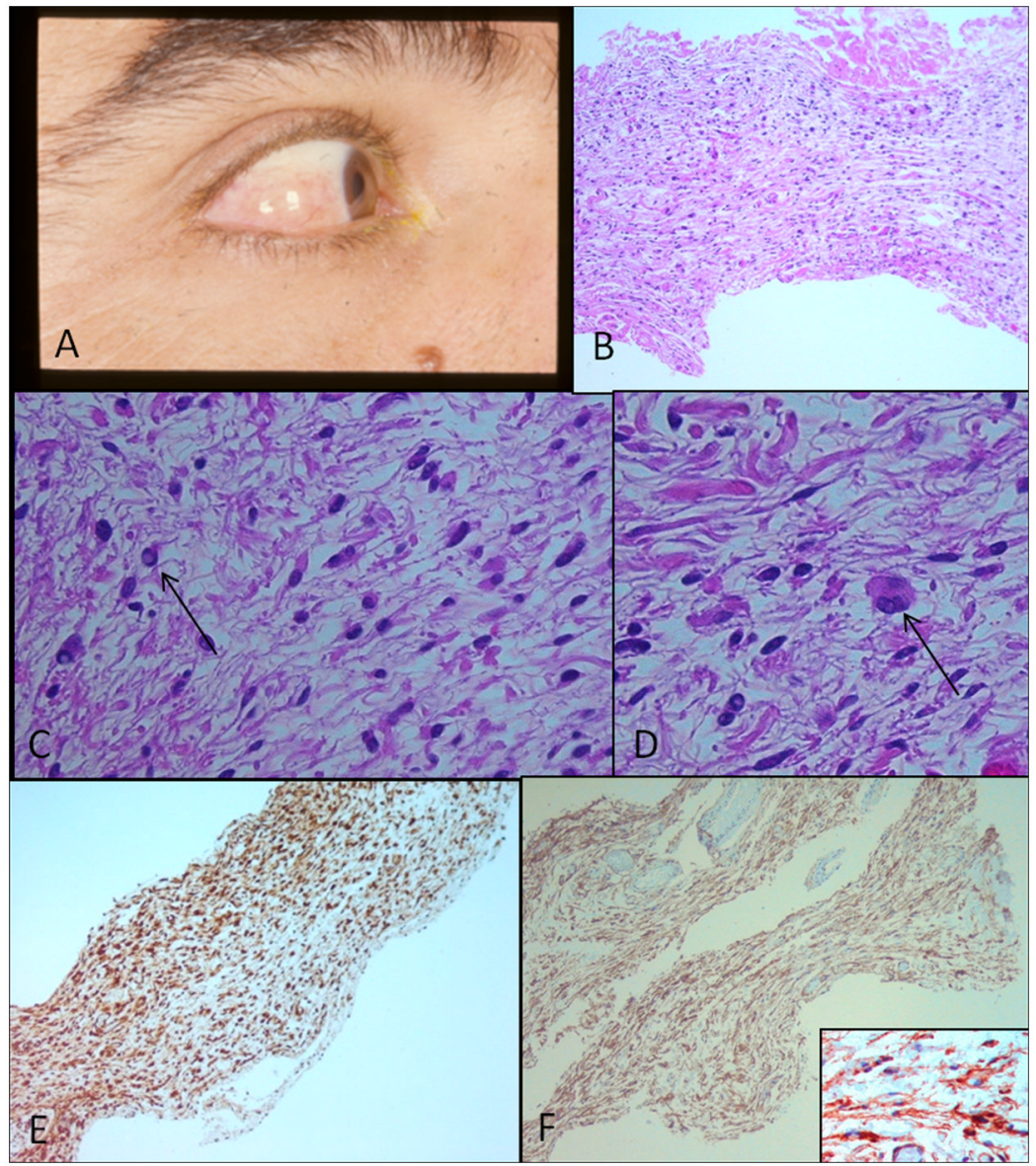

Figure 1.

Case 1. Clinical appearance showing a whitish to yellow lesion of the temporal bulbar conjunctiva (A). Histologic examination revealed a fibrocellular tumor with polymorphous nuclei (B; H\&E, 10x). Pseudonuclear inclusions (C, arrow; H\&E, 40x) and multinucleated cells (D, arrow; H\&E stain, 40x) were frequently observed. The spindle-shaped cells stained positive with myosin (E; myosin, 4x) and CD34 (F; CD34, 4x; insert: 40×). 


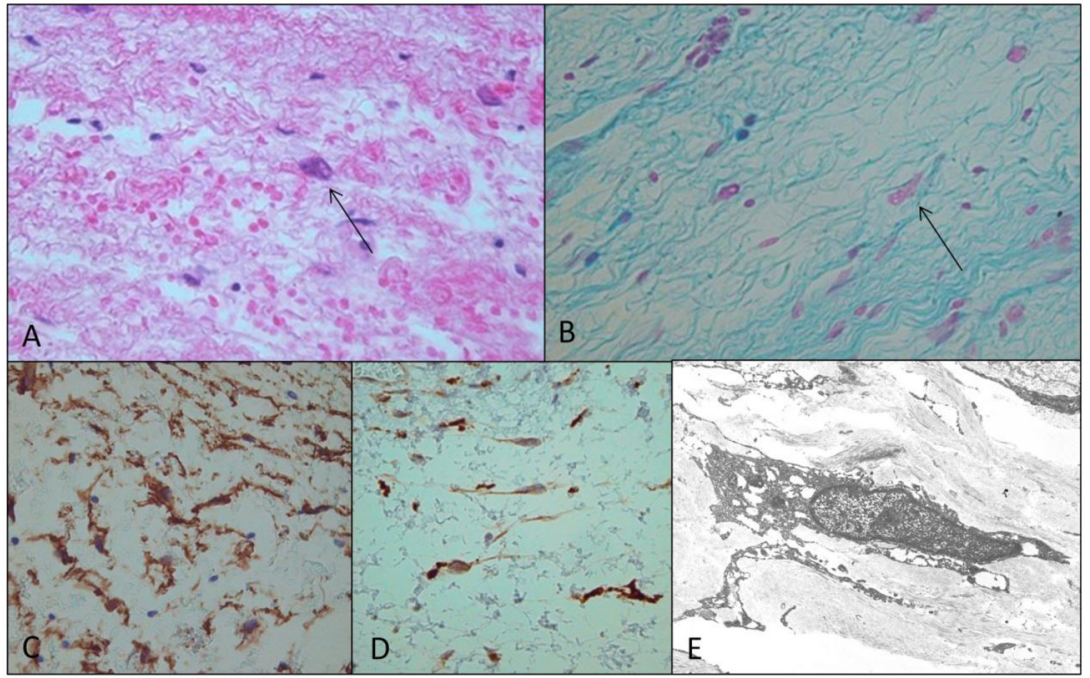

Figure 2.

Case 2. The tumor is composed of loosely arranged collagen fibers and some large cells with inclusions (A, arrow; H\&E, 40×). The extracellular matrix contained spindle-shaped cells with inclusions (arrow) and was positive for acid mucopolysaccharides (B; alcian blue, 40×). Immunohistochemical stains were positive for CD34 (C; CD34, 20x) in many areas and CD68 (D; CD68, 20x) in scattered macrophages. Transmission electron microscopy (TEM) revealed a spindle-shaped cell with branching processes and intracellular inclusions (E; TEM, 4655×). The cytoplasm contained rough endoplasmic reticulum and a few small mitochondriae but Golgi apparatus were not identified, the nuclear chromatin was equally dispersed. 


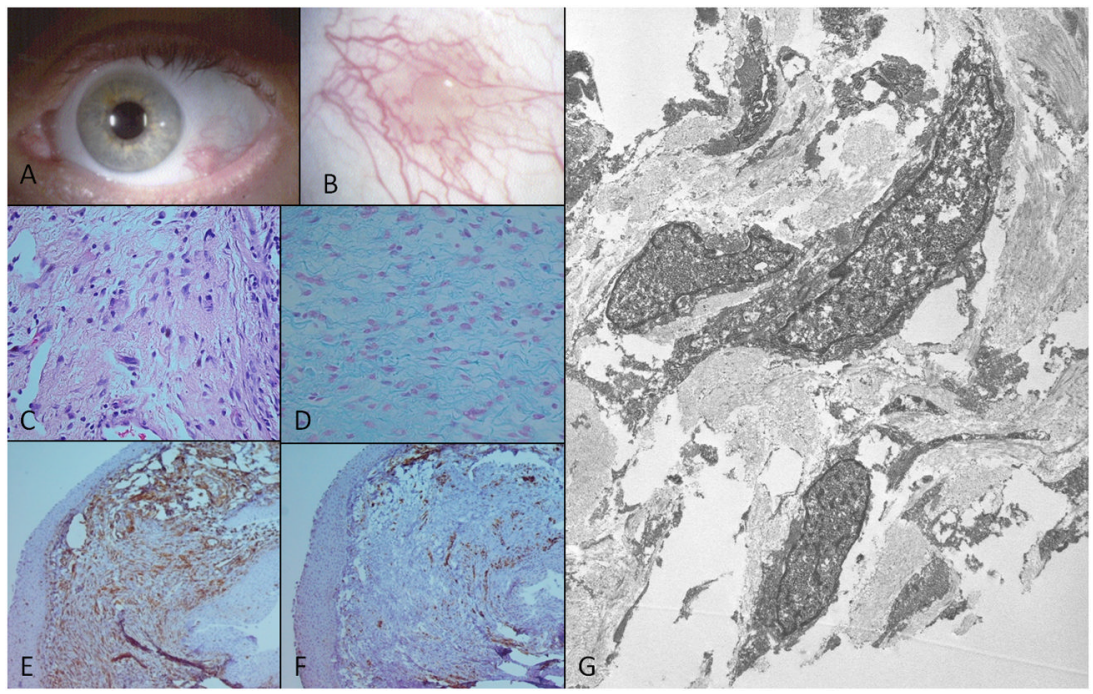

Figure 3.

Case 3. Clinical appearance showing a nodular lesion of the bulbar conjunctiva (A) surrounded by a vascular injection (B, higher magnification). Histology revealed polymorphous spindle-shaped cells (C; H\&E, 20x) with nuclear inclusions and an alcian blue positive extracellular matrix ( $\mathrm{D}$; alcian blue, 40x). Immunohistochemical stains were positive for vimentin (E; vimentin, 10×), CD34 (not shown), and CD68 in scattered macrophages (F; CD68, 10×). Transmission electron microscopy (TEM) showed a fusiform cell with branching processes as well as intracytoplasmic and intranuclear inclusions surrounded by plumper cells (G; TEM, 7018×). The cytoplasm contained rough endoplasmic reticulum. Mitochondriae and Golgi apparatus were not observed. The nuclear chromatin was equally dispersed and the nucleus showed infolding of its membrane. 


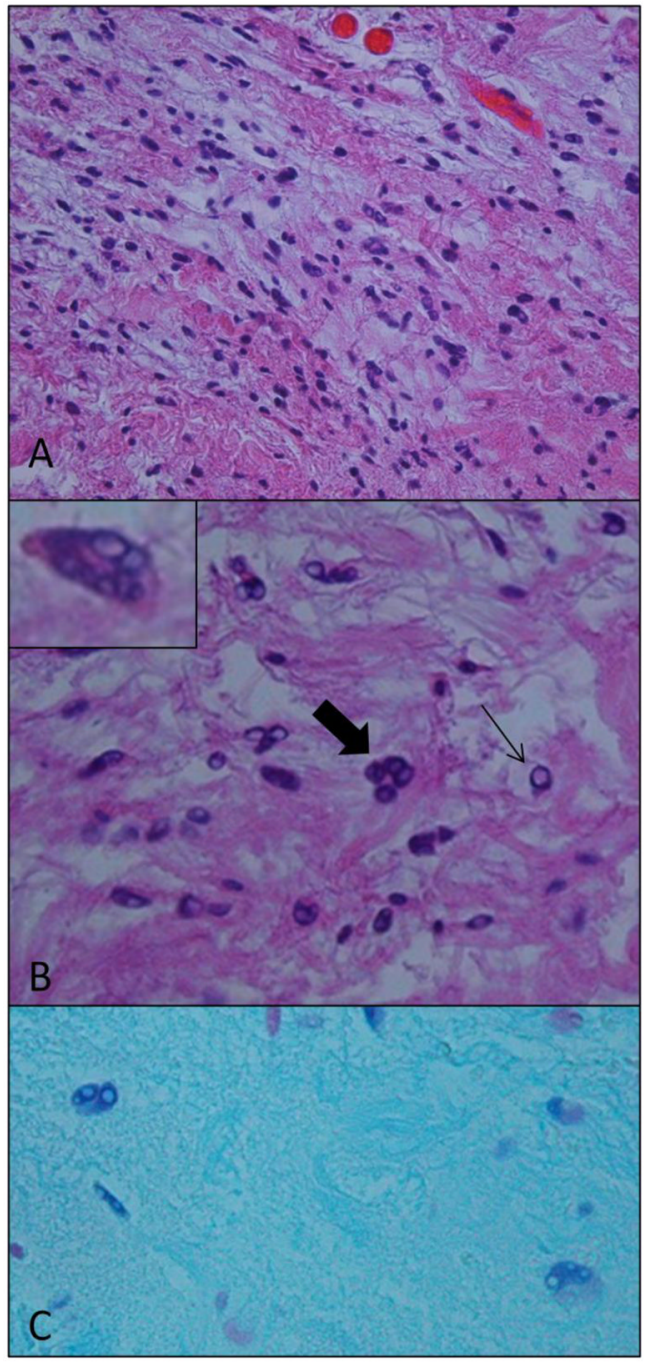

Figure 4.

Case 4. Spindle-shaped cells within a myxoid and collagenous matrix (A; H\&E, 20x). Nuclear inclusions (arrow) and floret-like multinucleated cells (bold arrow \& insert) are present $(\mathrm{B} ; \mathrm{H} \& \mathrm{E}, 40 \times)$. The stroma and some nuclei were alcian blue positive $(\mathrm{C}$; alcian blue, $40 \times)$. 


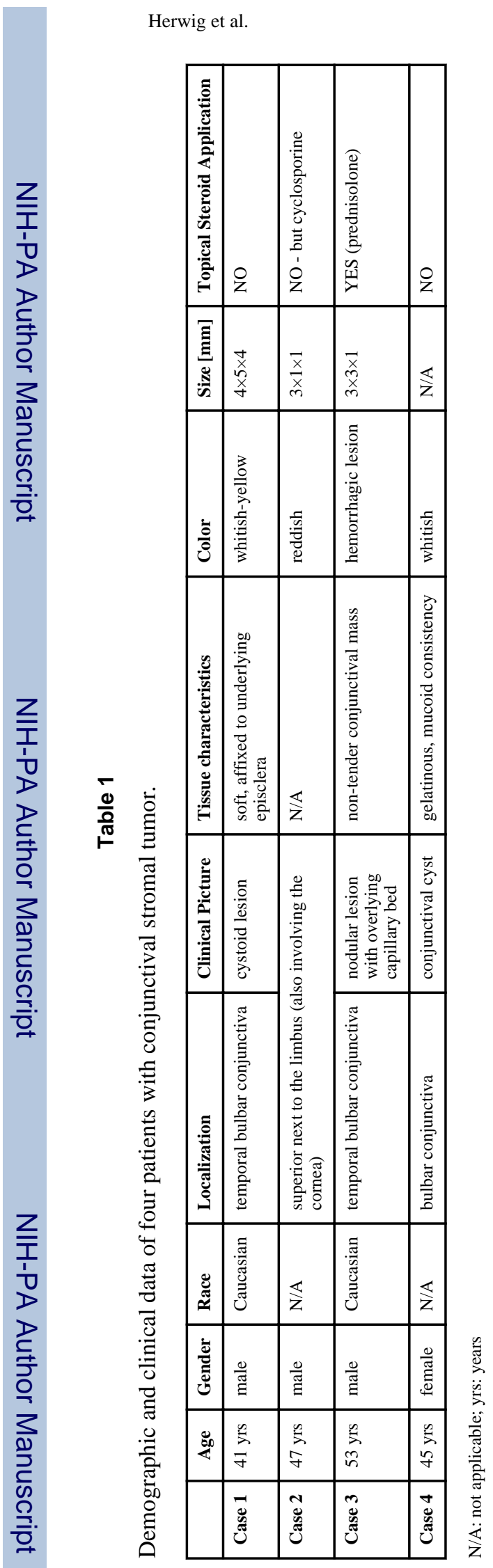

Ophthalmology. Author manuscript; available in PMC 2013 April 1. 

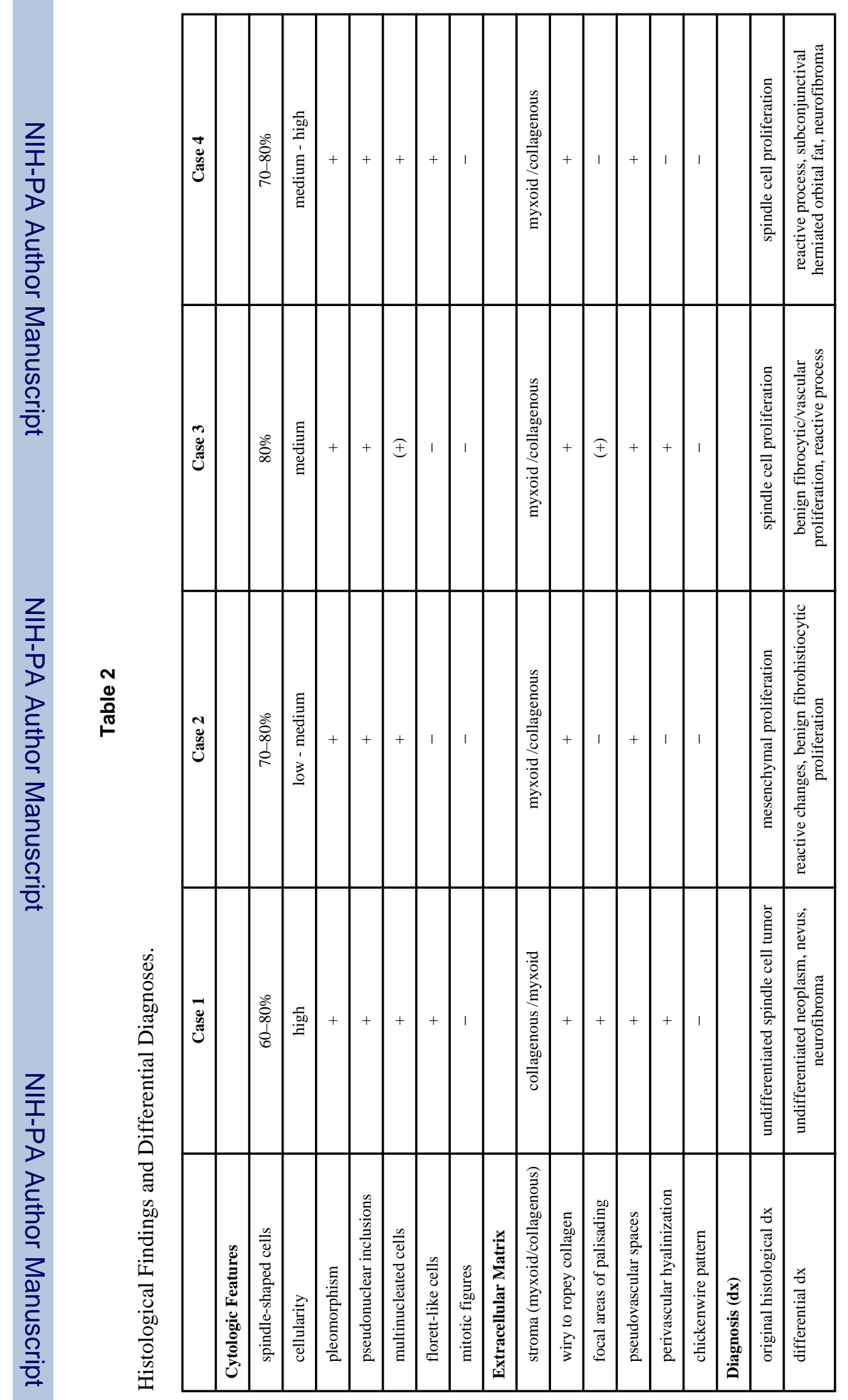

Ophthalmology. Author manuscript; available in PMC 2013 April 1. 


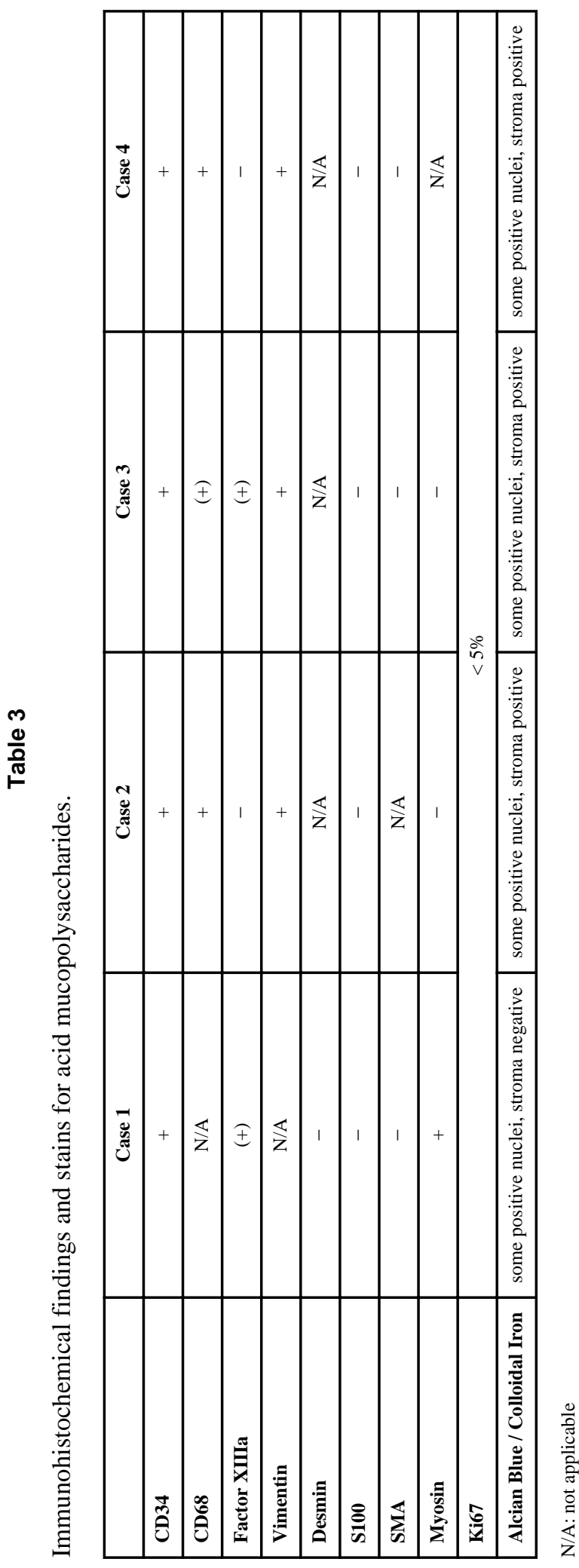

ב

Ophthalmology. Author manuscript; available in PMC 2013 April 1. 